\title{
A COMPARISON BETWEEN UNMANNED AERIAL VEHICLE AND AERIAL SURVEY ACQUIRED IN SEPARATE DATES FOR THE PRODUCTION OF ORTHOPHOTOS
}

\author{
Farsat HeEto Abdulrahman ${ }^{1}$, RAAD Awad Kattan and SAmi Mamlook Gilyana \\ Dept. Of Surveying Engineering, College of Engineering, University of Duhok, Kurdistan Region-Iraq
}

(Accepted for Publication: December 8, 2020)

\begin{abstract}
The Unmanned aerial vehicles (UAV) have become convenient for many applications such as the production of 3D ground models, orthophotos, road maintenance and dam monitoring, etc. The aim of this paper is to investigate the accuracy of the orthophoto obtained from UAV images compared to the existing orthophoto generated from aerial survey conducted by Vossing German Company in Duhok city, 2011 using GPS ground control point as a reference base. A digital elevation model (DEM) of the university campus was created with the UAV vertical images. Low flight height of $80 \mathrm{~m}$ was used with the rate of $70 \%$ forward overlap and 40\% side lap. An orthophoto is produced based on this DEM. To assess the accuracy of UAV orthophotos and the existing orthophotos produced from aerial survey, 7 ground control points (GCPs) were distributed and used for processing the orthophoto mosaic and DEM, 12 GCPs were used as check points. The 19 GCPs were accurately measured using GPS-RTK. Discrepancy in horizontal position of the GCPs measured on both orthophotos was obtained relative to the reference GPS base control points. The UAV data were processed and analyzed using two softwares pix4D and Agisoft Photoscan. The RMS errors obtained from both orthophotos is presented relative to the GPS base. Sub-centimetre accuracy for horizontal position was achieved from the UAV orthophoto at low flight altitude.
\end{abstract}

KEYWORDS: UAV images, Aerial photos, GPS-RTK, DEM, orthophotomosaic

\section{INTRODUCTION}

A ccuracy of the output of the UAV system is expected to meet most of engineering standards. Preliminary project studies can benefit from such application. Highway designers can utilize it in the early stages of route selection when high spatial coordinate accuracy is not a critical issue.

The automatic generation of digital elevation models (DEMs) has also gained attention in recent years. Many companies and research groups have made significant progress on this subject, and provide software packages or Web services for automatic generation of such 3D models. The common processing line for generating DEM depends on several factors such as overlapping, flight height, camera resolution, etc. The changes in these parameters affect the final accuracy of the model obtained, and many works analyzed the effects of each, (Brance P. Hudzietz \& Saripalli., 2012; Kung et al., 2011; Nagai, Tianen, Shibasaki, Kumagai, \& Ahmed, 2009).

(Wierzbicki, Kedzierski, \& Fryskowska, 2015) in their work assessed the accuracy of the UAV images tested in different weather and lighting conditions using INPHO UAS Master Program. Their results show that the quality and accuracy of UAV product degrade in worsened 
conditions by an average of $25 \%$ for the production of orthophoto.

(IDREES M \& ABULRAHMAN, 2020), assessed the accuracy of UAV images based DEM for calculating the volume using UAV, phantom pro4 in three altitudes $(25,50,100) \mathrm{m}$ with $80 \%$ forward and side overlaps on the same location at Duhok Dam. The GPS-RTK mode was also carried out for the same place and considered as a base for comparison. The results showed that the volume calculated with UAV images encountered $0.6 \%$ errors to the ground survey and concluded that low altitude of UAV does not improve the general accuracy of the results, but provides a better view of some finer surface details.

On the other hand, (Eisenbeiß, 2009) studied the UAV system in various applications. $\mathrm{He}$ obtained Orthophoto with $3 \mathrm{~cm}$ resolution of Pinchango Alto area produced from the UAV-images and DSM.

Also, (Norhayati Ngadimanthe, et al.2018) investigated the possibility of UAV in the production of orthophoto map of UTHM Pagoh Campus, two software were used, Agisoft photoScan for processing data and Pix4D for mission planning of the study area. The authors used different flight heights with different overlapped images. A total of 461 images were collected in their study area with DJI Phantom 4 Pro for an area which covered 0.251 sq.km. They focused on producing a decent quality of orthophoto map in their study area in order to benefit for more engineering applications, future planning and development.

The accuracy of Airsoft PhotoScan and Pix4D Mapper was investigated by (Muhammad
Faisal and Noradila Rusli, 2017). They compared these two software packages in order to evaluate the accuracy of orthophotos achieved by such software. The evaluation of accuracy of both software was based on the analysis of qualitative and quantitative data. The qualitative analysis contains the RMS error method for points and distance measurement. While the quality of the images was evaluated in the quantitative analysis. They found that the Agisoft PhotoScan was more powerful in both quantitative and qualitative analysis, but had less brightness regarding visual orthophoto when compared to the Pix4D Mapper.

In this paper the accuracy of the output of UAV images is investigated against the aerial survey system. The aim is to evaluate the expected accuracy of orthophoto generated from the output of UAV images compared to the existing orthophoto generated from aerial survey conducted by Vossing German Company in Duhok city, 2011 using GPS ground control point as a reference base of the same tested area of university of Duhok Campus, Duhok, Kurdistan region, Iraq.

\section{METHOD AND MATERIALS}

\subsection{Area of study}

The test area is located at the University of Duhok Campus College of engineering, Duhok city, Kurdistan region, Iraq. The geographical location of the center of the study area lies $36^{\circ}$ $51^{\prime} 23.04^{\prime \prime} \mathrm{N}$ and $42^{\circ} 54^{\prime} 55.65^{\prime \prime} \mathrm{E}$ as shown in Fig. (1. The place was irregular in terrain with which its size is approximately $250 \mathrm{~m}$ wide and $560 \mathrm{~m}$ long and the elevation ranges between $(485,506) \mathrm{m}$ above the mean sea level.

farst.heeto@uod.ac,rraadkattan@uod.ac, sami.gyliana@uod.ac

${ }^{1}$ Corresponding author: College of Engineering, University of Duhok, Kurdistan Region 


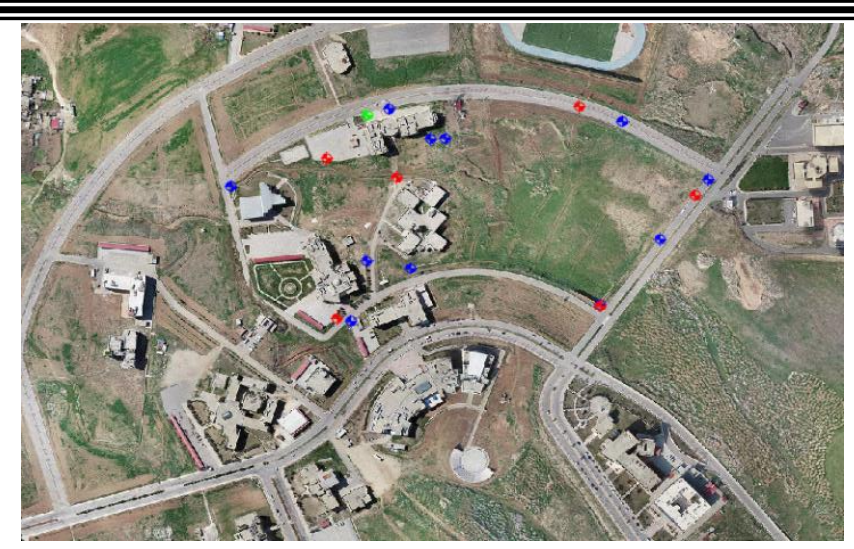

Fig. (1):. Area of study overlain GCPs represent in red color and check points represent in blue color

\subsection{UAV phantom 4 pro}

The low altitude image data was acquired using rotary wing UAV platform, phantom 4 pro, $4 \mathrm{~K}$ from DJI, which can be classified as state of the art in UAV systems as shown in Fig. (2. It is supplied with a 1-inch 20-megapixel sensor and has a manually adjustable aperture from F2.8 to F11. The camera Model FC6310 has a focal length $(\mathrm{f})=8.8 \mathrm{~mm}$, resolution $5472 \times 3648$ pixels / image and pixel size $2.41 \times 2.41 \mu \mathrm{m}$. It also supports auto-focus by half-pressing the shutter button, and has a focus range, from $1 \mathrm{~m}$ to infinity as well as five-direction sensors for avoiding obstacle (DJI., 2018). The UAV, Phantom 4 standard, permits fully autonomous flight at the specified height at a predetermined over-lap and side-lap image coverage. The system includes a flight remote controller that allows real-time flight parameter management.
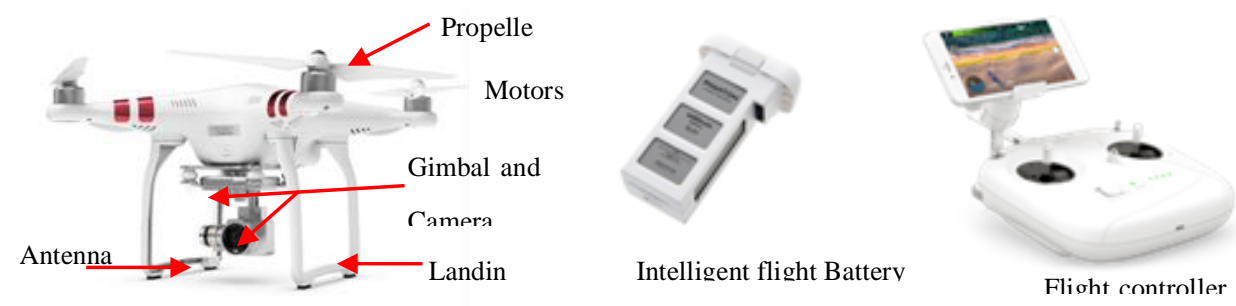

Fig. (2): DJI Phantom 4 pro, drone features

\subsection{The GPS system}

As a tool for measuring the GCPs and assessing the generated orthophotos by UAV images and aerial photos system, the GPS (Global Positioning System) was used. Leica viva GNSS receiver as shown in

Fig. (3, measures the incoming phase of the satellite signals to high level of precision in the range of a few millimeters in the repeated measurements (Hedgecock, Maroti, Sallai, Volgyesi, \& Ledeczi, 2013; Kattan, Abdulrahman, \& Hassan, 2016). The GPS-RTK mode in surveying is a method used in this study. The technical specification accuracy of such system stated by the manufacturer at single base are $\pm 8 \mathrm{~mm} \pm 1 \mathrm{ppm}$ for horizontal and $\pm 15 \mathrm{~mm}$ $\pm 1 \mathrm{ppm}$ for vertical component. The system was used for measuring all 19 GCPs coordinates in the vicinity of the study area. In the study area the GS10, GNSS receiver was set up on a highly accurate known control (C12) point. This point (C12) was previously measured with a static GPS in high precision by the university survey team. The GS15, GNSS receiver was used as a rover for measuring and recording data on the selected points for geo-referencing images taken by the UAV system. The coordinate system used for measurements was the WGS84, UTM-38N projection. 


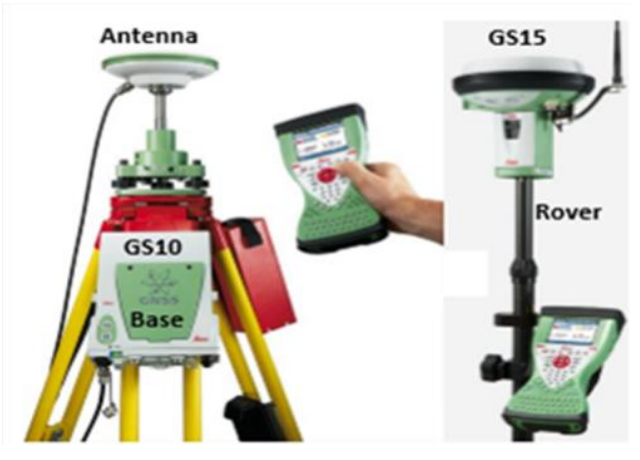

Fig. (3) Leica viva GNSS receiver GS10 Base station and GS15 rover

\subsection{Data collection}

265 images were collected using UAV flown over the test area at altitudes of $80 \mathrm{~m}$, with 11 flight path lines in the South East to North West direction. Front and side overlap coverage were set to $70 \%$ and $40 \%$ respectively as illustrated in Table (1. In the field study, total 19 GCPs (measured using RTK system), among them 7 GCPs were used to assist spatial referencing process of images which implies to compute the scale, orientation and absolute position of the outputs in a desired coordinate system (Zietara, 2017). The remaining 12 GCPs used as check points for evaluating the accuracy of the orthophotomosaic. GCPs were measured using GNSS, Leica Viva GS10 receiver used as a base and GS15 receiver as a rover in the UTM WGS84- $38 \mathrm{~N}$ coordinate system. The size of GCPs targets was $(0.6 \mathrm{~m} \times 0.6 \mathrm{~m})$. All GCPs were distributed in somehow to cover the area of interest.

Pix4D Capture was used for flight planning which is an autopilot application available for both systems, Android and IOS. The software allows the user to select the desired height of flight, percent of overlap of images and shape of the mapping area. After powering on and pressing the START button, it will fly the planned mission automatically (Pix4D, 2020).
Table (1): The specification of collecting data

\begin{tabular}{ll}
\multicolumn{2}{c}{ by UAV } \\
\hline Parameters & altitude \\
\hline Flight height & $79.4 \mathrm{~m}$ \\
\hline Flight time (minute) & 36 \\
\hline coverage area $\left(\mathrm{m}^{2}\right)$ & $0.235 \mathrm{~km}^{2}$ \\
\hline Forward overlap \% & $70 \%$. \\
\hline Side overlap \% & $40 \%$ \\
\hline GSD cm/pixel & 1.97 \\
\hline Flight lines & 11 \\
\hline Number of images & 265 \\
\hline
\end{tabular}

\section{FIELD MEASUREMENTS AND RESULT ANALYSIS \\ 3.1 UAV survey at the University of Duhok campus}

The survey campaign was planned to cover the college of engineering site, the flight was performed in June, 2020 at 11:00 o'clock in a calm weather condition covering $500 \mathrm{~m}$ x $1000 \mathrm{~m}$ area. The height of the sun was suitable over the horizon and the sky visibility was clear without wind. The flight was planned for automatic takeoff, flight and landing in Pix4D Capture software. During this flight campaign, 265 images were taken at the flight height of $80 \mathrm{~m}$, with ground pixel resolution equal to $1.97 \mathrm{~cm} /$ pixel. The strip directions and size of coverage of each spot are shown in

Fig. (4. The size of coverage for each spot is indicated in different colors. The dark blue indicates more than 9 repeated coverage. The outer boundaries are covered with two or one images.

farst.heeto@uod.ac, raadkattan@uod.ac, sami.gyliana@uod.ac

${ }^{1}$ Corresponding author: College of Engineering, University of Duhok, Kurdistan Region 


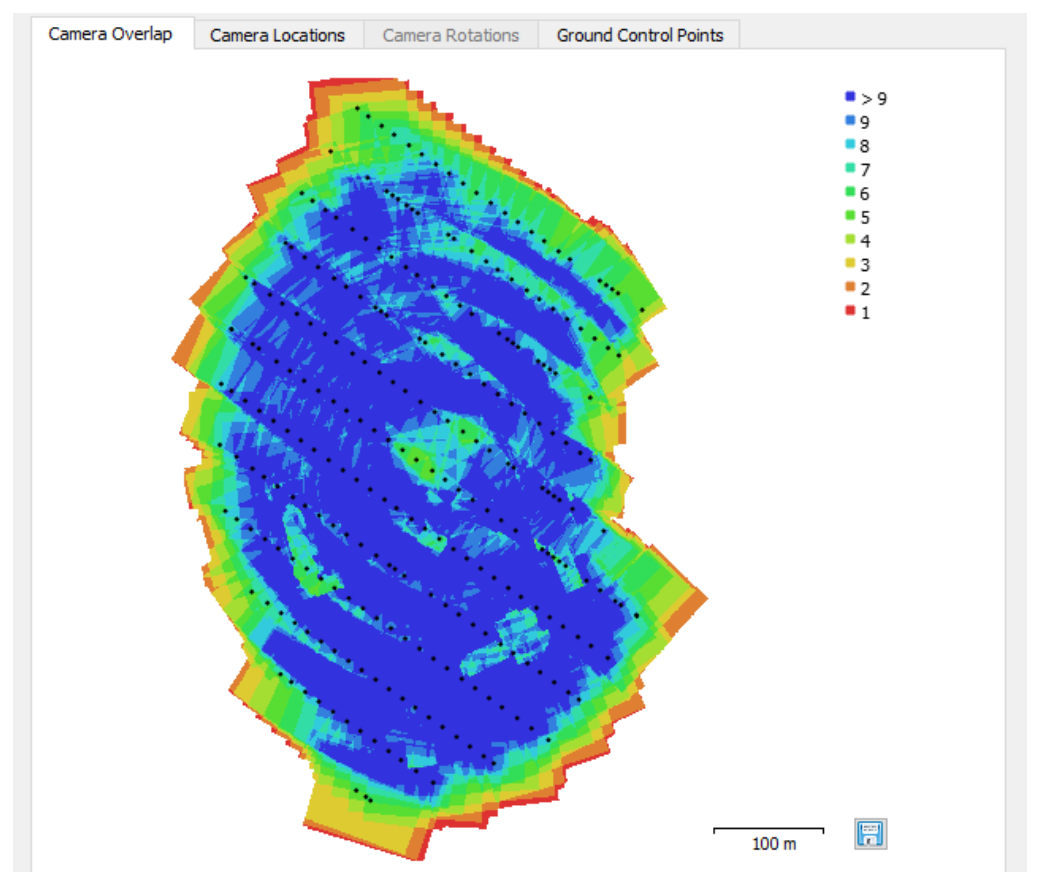

Fig. (4): Number of overlapping images over the study area overlain the strip direction of flight.

Sample of the captured images taken by UAV is shown in

Fig. (5. Fig. (6 shows a sample of a GCPs appear in one image. The coordinates of Ground Control points measured using GPS-RTK are listed in

\section{Table $(2$.}

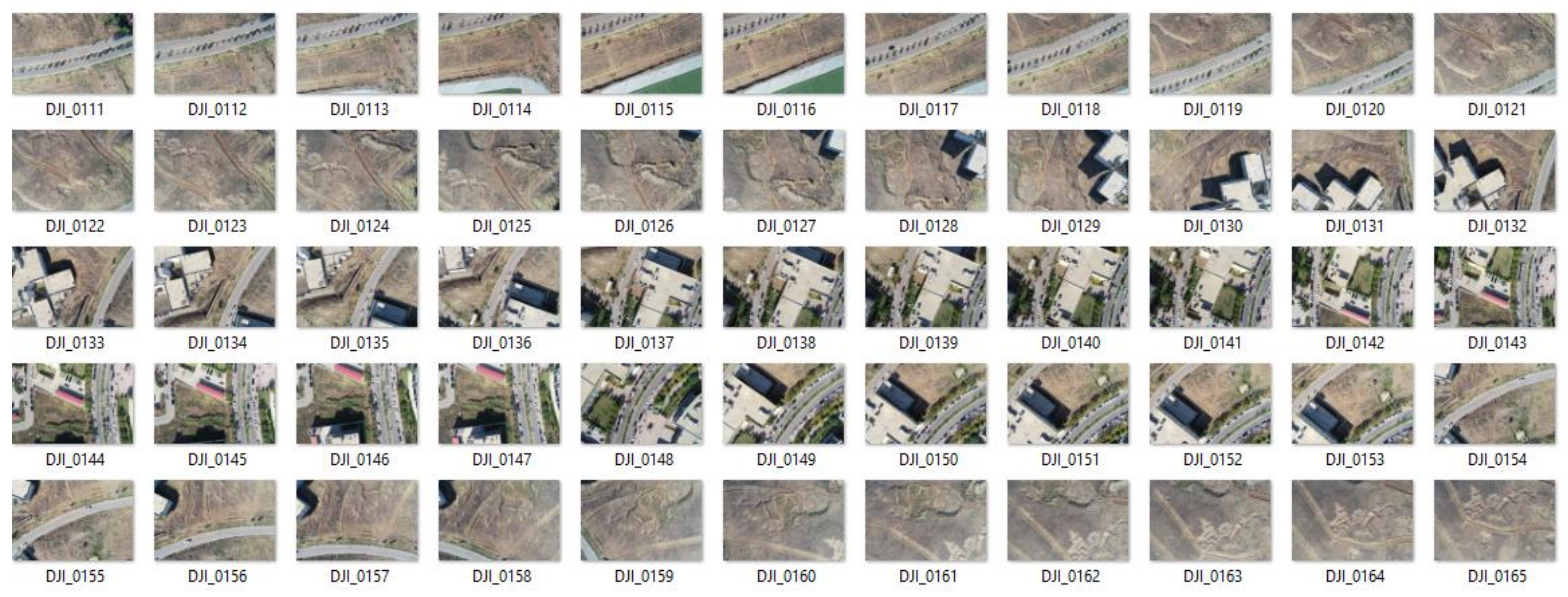

Fig. (5): A sample of images taken by UAV at $80 \mathrm{~m}$ altitude.

farst.heeto@uod.ac, raadkattan@uod.ac, sami.gyliana@uod.ac ${ }^{1}$ Corresponding author: College of Engineering, University of Duhok, Kurdistan Region 


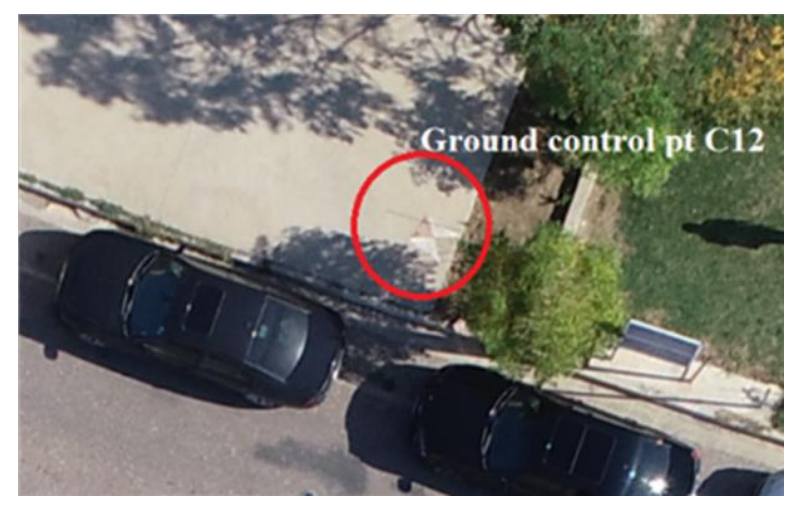

Fig. (6): A sample of GCPs appear in the image taken by UAV at $80 \mathrm{~m}$ altitude.

Table (2): GCPs around the study area

\begin{tabular}{lccc}
\hline \multicolumn{1}{c}{ Points } & $\mathrm{E}$ & $\mathrm{N}$ & height \\
\hline C1 & 314297.349 & 4081166.202 & 500.497 \\
\hline C2 & 314037.581 & 4081140.622 & 498.184 \\
\hline C12 & 314049.131 & 4080883.967 & 490.776 \\
\hline C13 & 314105.073 & 4080835.418 & 488.356 \\
\hline C-Bridge & 314130.202 & 4080920.054 & 489.229 \\
\hline C-car park & 314313.760 & 4080847.514 & 489.346 \\
\hline C-Manhole & 314153.573 & 4081280.601 & 506.401 \\
\hline
\end{tabular}

The UAV Pentium 4 provides initial exposure centre coordinates within accuracy of $10 \mathrm{~m}$. These coordinates are measured using a built in standalone GPS system. Samples of Camera exposure stations with exposure centre coordinate are shown in Table (3.

Table (3): Camera exposure station with exposure centre coordinate measured by the built in GPS

\begin{tabular}{|c|c|c|c|c|c|c|}
\hline \multicolumn{2}{|c|}{ Cameras } & \multirow{2}{*}{$\begin{array}{l}\text { Longitude } \\
42.914960\end{array}$} & \multirow{2}{*}{$\begin{array}{l}\text { Latitude } \\
36.854016\end{array}$} & \multirow{2}{*}{$\begin{array}{l}\text { Altitude }(\mathrm{m}) \\
523.825000\end{array}$} & \multirow{2}{*}{$\begin{array}{l}\text { Accuracy }(\mathrm{m}) \\
10.000000\end{array}$} & \multirow{2}{*}{$\begin{array}{l}\text { Error }(\mathrm{m}) \\
26.809778\end{array}$} \\
\hline 鸟 & Dנ_0001 & & & & & \\
\hline 고 & DJ_0002 & 42.915022 & 36.853985 & 523.925000 & 10.000000 & 27.268839 \\
\hline$\checkmark 9$ & DII_0003 & 42.915108 & 36.853935 & 523.825000 & 10.000000 & 26.801341 \\
\hline$\checkmark 9$ & DJ_0004 & 42.915752 & 36.854092 & 523.825000 & 10.000000 & 26.460489 \\
\hline 口 & DJ_0005 & 42.915587 & 36.854179 & 523.925000 & 10.000000 & 26.226376 \\
\hline 鸟 & DJ_0006 & 42.915441 & 36.854258 & 524.025000 & 10.000000 & 26.036974 \\
\hline 口 & DJ_0007 & 42.915297 & 36.854339 & 524.025000 & 10.000000 & 25.928841 \\
\hline 口 & DЛ_0008 & 42.915158 & 36.854416 & 524.025000 & 10.000000 & 25.777570 \\
\hline 口 & DJl_0009 & 42.915016 & 36.854491 & 523.925000 & 10.000000 & 25.761491 \\
\hline 口 & DJ_0010 & 42.914874 & 36.854567 & 523.925000 & 10.000000 & 25.695102 \\
\hline 口 & DJ_0011 & 42.914734 & 36.854642 & 523.925000 & 10.000000 & 25.553459 \\
\hline 口 & DJI_0012 & 42.914593 & 36.854718 & 524.025000 & 10.000000 & 25.396744 \\
\hline 口 & DI_0013 & 42.914451 & 36.854795 & 523.925000 & 10.000000 & 25.354838 \\
\hline$\checkmark \longdiv { 1 9 }$ & DII 9014 & 42.914311 & $36.85487 ?$ & 523.925000 & $10.0 \cap 0 \cap \Omega \cap$ & 25.277011 \\
\hline
\end{tabular}

farst.heeto@uod.ac, raadkattan@uod.ac, sami.gyliana@uod.ac

${ }^{1}$ Corresponding author: College of Engineering, University of Duhok, Kurdistan Region 


\subsection{Image processing}

After aligning images and adding the location of GCPs for geo-referencing, several trials for refinement of the images are necessary to reduce the errors in coordinates of the control points. In the first refinement stage, the programme, Agisoft PhotoScan software selects a few or no images that contain the marker using filter the photos by marker option. After the optimization and allowing for the calculations of the camera calibration and the internal orientation parameters, $(\mathrm{Cx}, \mathrm{Cy}, \mathrm{B} 1, \mathrm{~B} 2, \mathrm{~K} 1, \mathrm{~K} 2, \mathrm{~K} 3, \mathrm{P} 1$ and P2) and after several refinement stages the accuracy of the GCPs achieved on the images will be stabilized to minimum. These errors can be shown in Table (4. The GCP locations and error estimates are presented. The $\mathrm{Z}$ error is represented by colored ellipses as depicted in Fig. (7. Horizontal position (E, N) errors are represented as ellipse shapes scaled up to 1000 times. The colors represent the size of error in elevations. The figure shows the size of error before and after the refinement process.
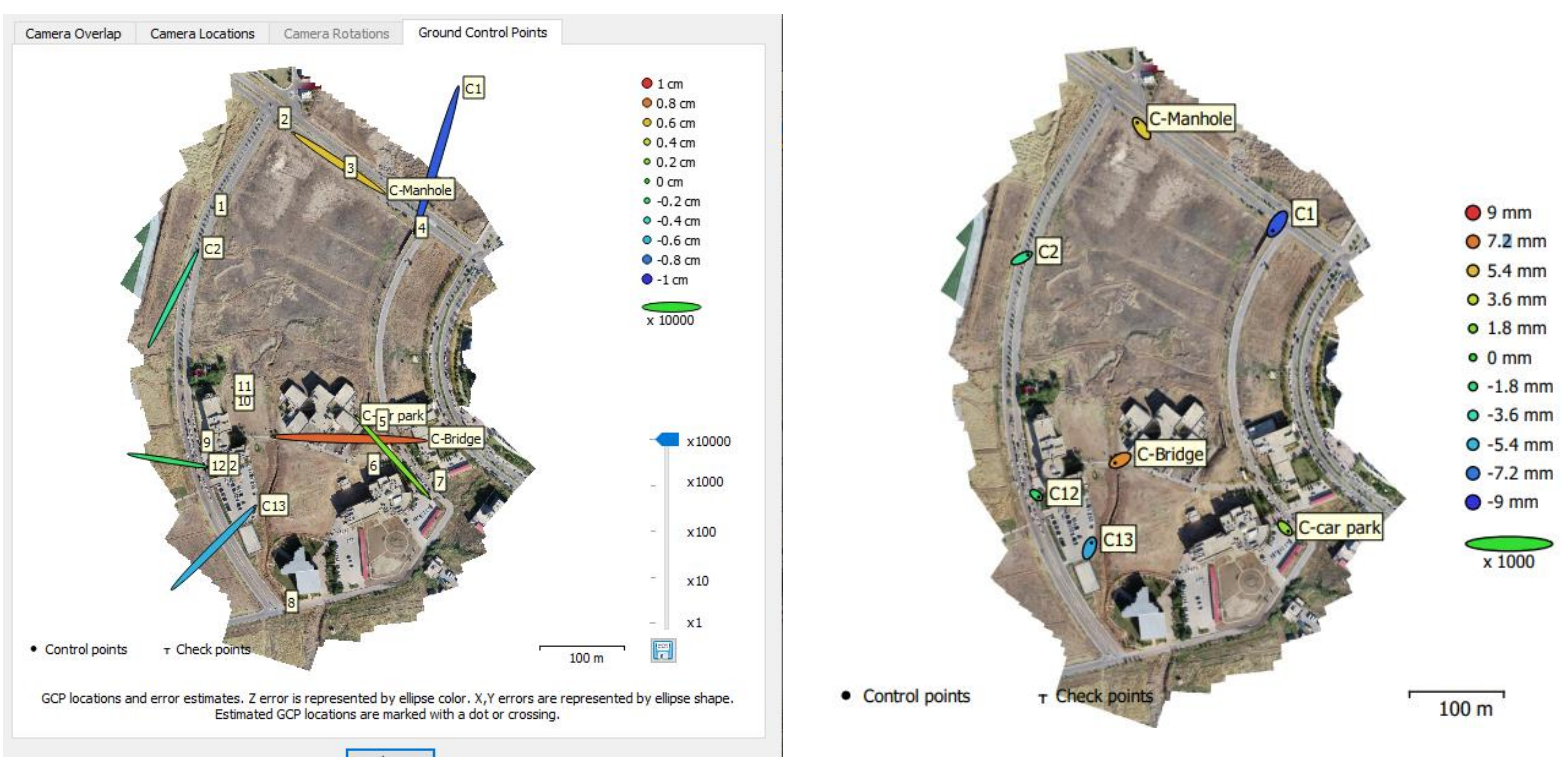

Fig. (7): GCP locations and error estimates

Table (4): Control points, RMSE

\begin{tabular}{|c|c|c|c|c|c|c|}
\hline Label & X error $(\mathrm{cm})$ & $Y$ error $(\mathrm{cm})$ & error & error & Total & Image \\
\hline C1 & -0.962 & -1.415 & -0.812 & 1.711 & 1.894 & $0.263(7)$ \\
\hline $\mathrm{C} 2$ & 1.320 & 0.690 & -0.227 & 1.489 & 1.507 & $0.237(7)$ \\
\hline $\mathrm{C} 12$ & 0.524 & -0.394 & -0.146 & 0.655 & 0.671 & $0.292(11)$ \\
\hline $\mathrm{C} 13$ & 0.424 & 1.122 & -0.592 & 1.199 & 1.337 & $0.241(12)$ \\
\hline C-Bridge & -1.034 & -0.548 & 0.666 & 1.170 & 1.346 & $0.807(10)$ \\
\hline C-Car park & 0.671 & -0.662 & 0.261 & 0.942 & 0.977 & $0.273(16)$ \\
\hline C-Manhole & -0.928 & 1.235 & 0.512 & 1.545 & 1.628 & $0.474(7)$ \\
\hline Total & 0.887 & 0.934 & 0.515 & 1.291 & 1.389 & 0.410 \\
\hline
\end{tabular}


Table (4. Shows the RMSE of the coordinates of the Control points in $\mathrm{X}$ - Easting, Y - Northing, Z-Altitude

\subsubsection{Build dense cloud}

In this step 36,992,984 points were generated as point cloud, and these points exported to the Autodesk Recap software as, ASPRS LAS (*.Las) file format. The dense clouded file size is 917MB.

\subsubsection{DEM model generation}

The DEM generated assign a colour for different elevation ranges proved and on revering over the DEM, UTM coordinates are displayed. The size of the reconstructed Digital Elevation Model (DEM) was 8,023 x 11,037 created with resolution $7.86 \mathrm{~cm} /$ pix and point density 162 points $/ \mathrm{m}^{2}$ as shown in the Fig. ( 8 . Contour lines can be generated and added at this stage.

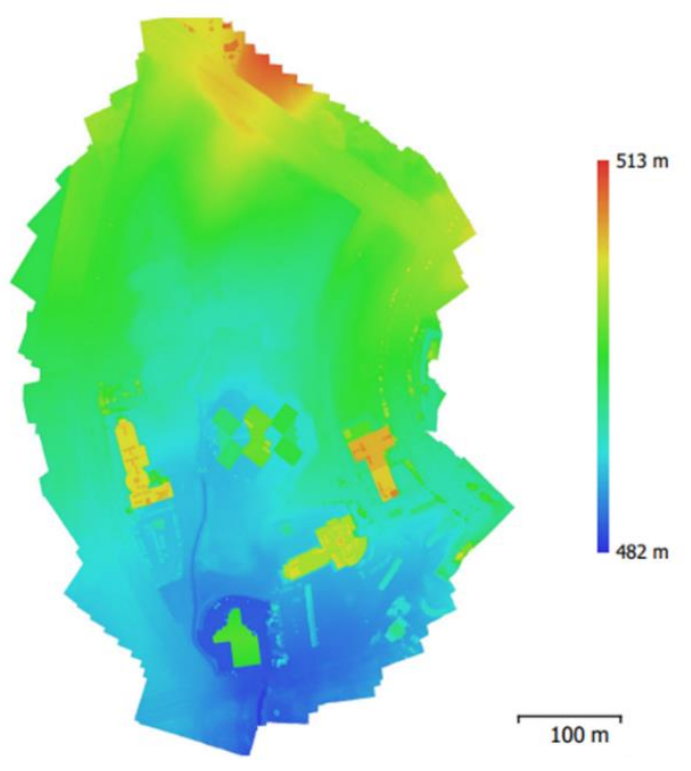

Fig. (8): Reconstructed digital elevation model

\subsubsection{Orthomosaic generation}

The size of the generated orthomosaic was 25,427 x 36,675 as shown in Fig. (9. It is produced in true colour and texture. On moving a curser over the orthomosaic, UTM coordinates are displayed. Contour lines can also be generated and added to the orthomosaic.

farst.heeto@uod.ac, raadkattan@uod.ac, sami.gyliana@uod.ac

${ }^{1}$ Corresponding author: College of Engineering, University of Duhok, Kurdistan Region 


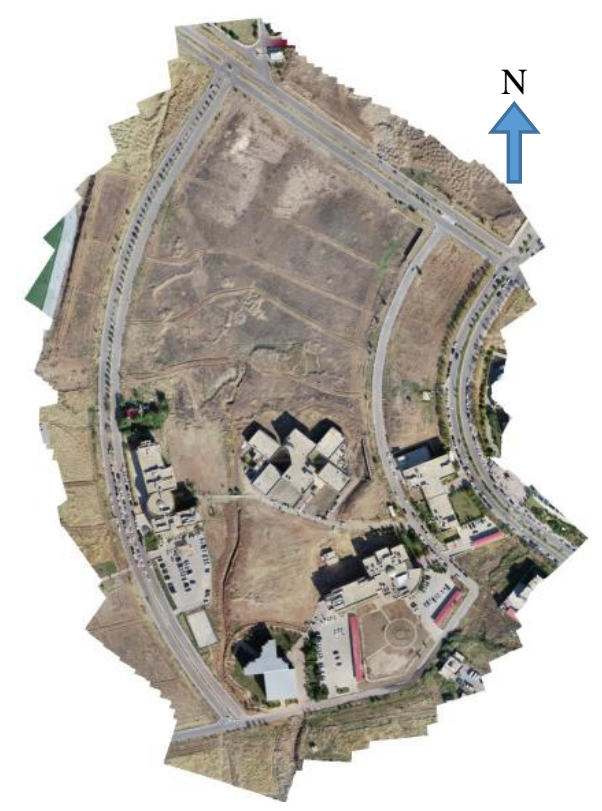

Fig. (9): Orthomosaic, colour 3 bands, uint8 with coordinates system WGS 84 / UTM zone 38N

The orthomosaic exported as a Tiff (*.tif) image to be used later as a base to produce the final Orthomosaic using the AutoCAD civil 3D.

\subsubsection{DEM transfer}

The dense cloud, ASPRS LAS (*.Las) exported from Agisoft will be opened in the
Autodesk recap software as a step in reducing the size of the file. Fig. (10 shows a sample of dense cloud generated by a ReCap software. Then the dense cloud is exported as a RCS (*. rcs) file format. The data size is reduced to 784 MB.
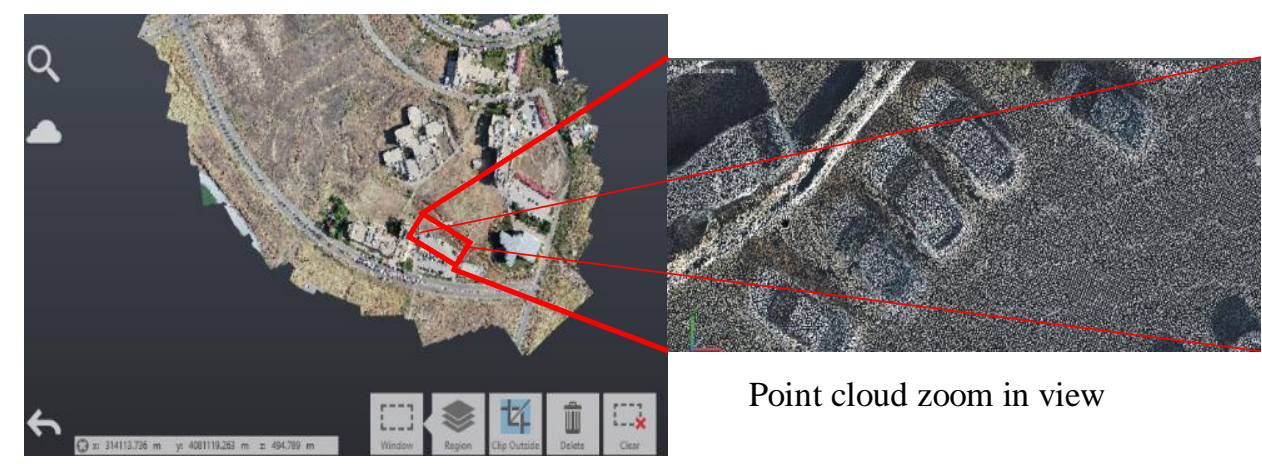

Fig. (10): The Dense cloud of points extracted from Autodesk ReCap

\subsubsection{AutoCAD Civil 3D processing}

The dense cloud generated from the recap and the orthomosaic generated from the Agisoft PhotoScan software are combined to produce the final site Orthophomosaic in the AutoCAD civil 3D. In addition, contour lines are displayed with minor $1 \mathrm{~m}$ and major $5 \mathrm{~m}$ intervals. Fig. (11 shows the total area with the UTM grid and zoom in view to show part of the study area. The figure also shows an orbital view of a part of the site, demonstrating contour lines that delimit the perspective view of the building as contour lines.

farst.heeto@uod.ac, raadkattan@uod.ac, sami.gyliana@uod.ac ${ }^{1}$ Corresponding author: College of Engineering, University of Duhok, Kurdistan Region 


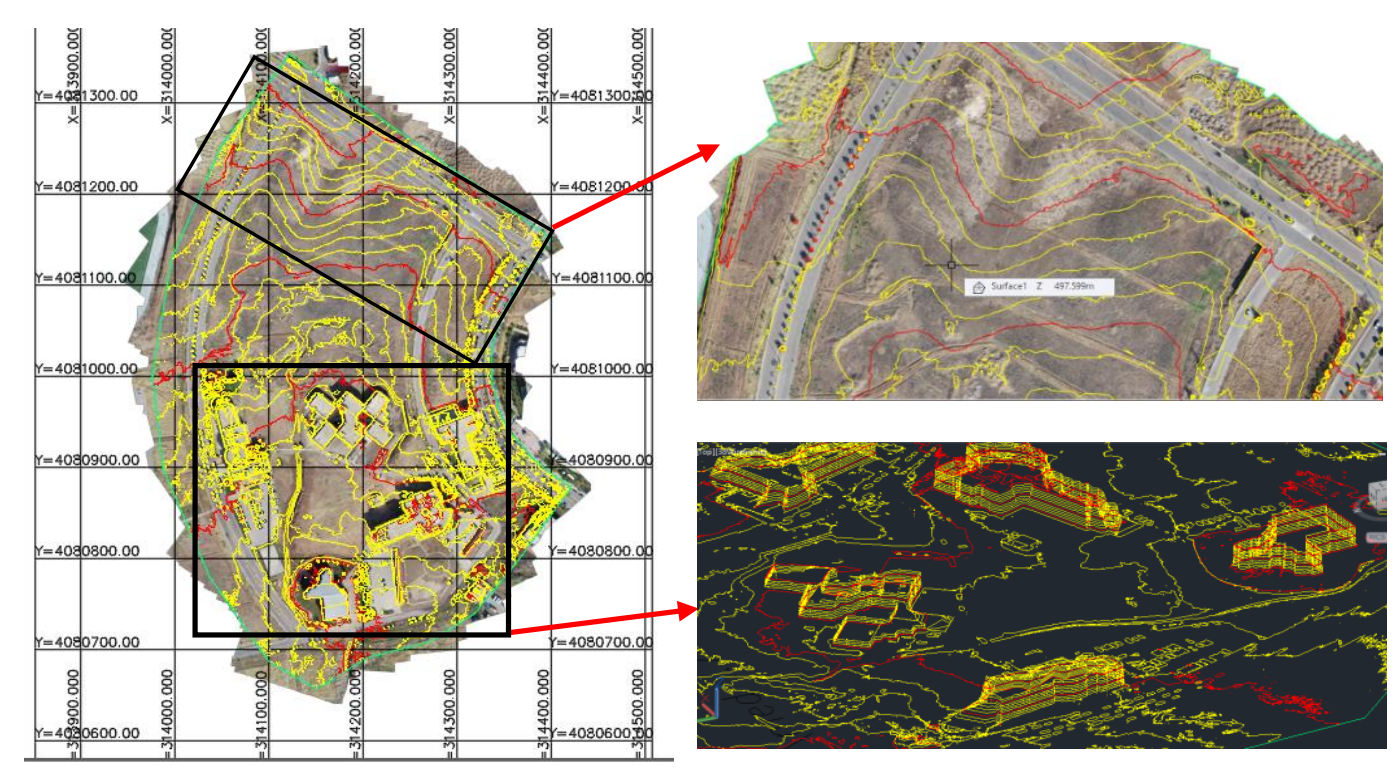

Fig. (11): The orthomosaic overlain grid coordinates and contour map, left photo. Right photo, contour map zoom in view and perspective building view as a contour lines.

\subsubsection{The properties of orthophotos}

Although the original image contains relief displacement, the top of the image appears inclined outward relative to the bottom of the object or building. The top of it appears a bit far from the bottom. Images are appeared aligning away from radial straight line from the centre of image. For example, if the height of the building appears and if its located far from the centre then the top of the building will not coincide with its bottom as shown in the Error! Reference source not found.,a. In the other words, an inclination in the elevation of a certain element results in its photographic position to be moved radially in an outward direction from the primary point. When a vertical element is photographed, the relief displacement affects the top of the element causing it to be located at a distant from the central position of the photograph than its base. Thus, vertical elements are shown to lean away from the central part of the photograph.

However, the orthophoto is a real vertical projection, the top of the building appears to coincide with the bottom of it as illustrated in Figure 12, b. The façade of the building cannot be shown. The real UTM coordinates and elevations can be displayed in the orthophotos. The only trouble with orthophotos is that trees, buildings and vehicles (temporary features) will appear. So work has to be done to filter these temporary objects such as moving vehicles, trees and etc. The features of the orthophoto include topographic relief, lens distortion and camera tilts; thus, it can be used to measure accurate distances. This makes it a true representation of the earth's surface.

farst.heeto@uod.ac, raadkattan@uod.ac, sami.gyliana@uod.ac

${ }^{1}$ Corresponding author: College of Engineering, University of Duhok, Kurdistan Region 


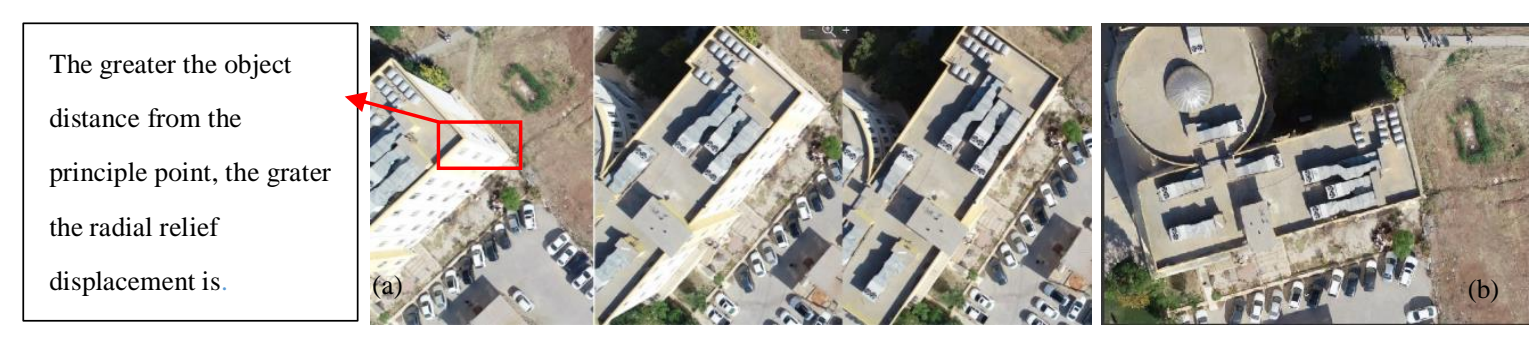

Fig. (12. a): Relief displacements on high building, b) Orthophotos without relief displacement

A sector of existing orthomosaic of the same tested area was conducted by Vossing German compamy used for comparison with UAV which produced Orthophomosaic and the results can be explained in the following section.

\section{RESULTS}

The mean and standard deviation of the measured points from AutoCAD Civil 3D using surface generated from Agisoft and transferred via Autodesk Recap software plus the orthomosaic generated from Agisoft. The results are depicted in Table ( 5 with GCPs.

Table (5): The mean and standard deviation of the UAV orthomosaic vs GCPs

\begin{tabular}{|c|c|c|c|c|c|c|c|c|c|}
\hline \multirow{2}{*}{$\begin{array}{l}\text { GCPs } \\
\mathrm{C} 1\end{array}$} & \multicolumn{3}{|c|}{ GPS control points $(\mathrm{m})$} & \multicolumn{3}{|c|}{ Orthomosaic generated from Agisoft } & \multirow{2}{*}{$\frac{\Delta \mathrm{E}(\mathrm{m})}{-0.006}$} & \multirow{2}{*}{$\frac{\Delta \mathrm{N}(\mathrm{m})}{-0.024}$} & \multirow{2}{*}{$\frac{\Delta \mathrm{h}(\mathrm{m})}{-0.149}$} \\
\hline & 314297.3 & 4081166.2 & 500.497 & 314297.3 & 4081166.2 & 500.3 & & & \\
\hline $\mathrm{C} 2$ & 314037.6 & 4081140.6 & 498.184 & 314037.5 & 4081140.6 & 498.1 & -0.034 & 0.008 & -0.087 \\
\hline C12 & 314049.1 & 4080884.0 & 490.776 & 314049.1 & 4080884.0 & 490.8 & -0.015 & 0.020 & -0.019 \\
\hline $\mathrm{C} 13$ & 314105.1 & 4080835.4 & 488.356 & 314105.0 & 4080835.4 & 488.4 & -0.046 & 0.019 & -0.006 \\
\hline C-Bridge & 314130.2 & 4080920.1 & 489.229 & 314130.2 & 4080920.1 & 489.2 & -0.028 & 0.026 & 0.013 \\
\hline C-Car park & 314313.8 & 4080847.5 & 489.346 & 314313.7 & 4080847.5 & 489.4 & -0.011 & -0.008 & 0.045 \\
\hline C-Manhole & 314153.6 & 4081280.6 & 506.401 & 314153.6 & 4081280.6 & 506.4 & -0.018 & -0.016 & -0.022 \\
\hline \multicolumn{7}{|c|}{ Mean } & -0.022 & 0.003 & -0.032 \\
\hline \multicolumn{7}{|c|}{ Standard deviation (St.dev.) } & 0.014 & 0.020 & 0.065 \\
\hline
\end{tabular}

Table (5 shows a discrepancy range of (-0.0056 to -0.0456$),(-0.0081$ to 0.02$)$, and $(-0.0055$ to 0.0448$)$ in Easting, Northing and elevation respectively. At these ranges, the amount of errors can be acceptable in most of engineering surveying applications.

Regarding the GCPs selected for modelling in the study area, most of the points cannot be identified with the existing orthophomosaic conducted by Vossing German Company, 2011. Only two points, $\mathrm{C} 1$ and $\mathrm{C} 2$, were identified on both orthomosaic and the discrepancy range of such points (C1 and $\mathrm{C} 2)$ in Easting, Northing and elevation encountered to the GCPs are $(-0.0198,-0.0658,-2.8856) \mathrm{m}$ and $(-0.0598$, $-0.0402,-0.2713) \mathrm{m}$ respectively.

By the same way, the mean value and standard deviation between the two orthomosaics (UAV and aerial survey) were achieved with 12 check points on the same tested area. The discrepancy results of both orthomosaics can be shown in the Table $(6$ and Table $(7$. 
Table (6): The mean and standard deviation of the UAV orthomosaic vs Check points

\begin{tabular}{cccccccccc}
\hline Points & \multicolumn{2}{c}{ GPS check points $(\mathrm{m})$} & \multicolumn{1}{c}{ Orthomosaic generated from Agisoft $(\mathrm{m})$} & $\Delta \mathrm{e}(\mathrm{m})$ & $\Delta \mathrm{n}(\mathrm{m})$ & $\Delta \mathrm{h}(\mathrm{m})$ \\
\hline 1 & 314057.0 & 4081192.7 & 497.963 & 314056.9 & 4081192.7 & 498.0 & -0.037 & -0.014 & 0.056 \\
\hline 2 & 314132.8 & 4081296.5 & 505.268 & 314132.8 & 4081296.5 & 505.3 & 0.004 & -0.017 & -0.005 \\
\hline 3 & 314210.8 & 4081238.0 & 503.388 & 314210.8 & 4081238.0 & 503.5 & 0.010 & -0.011 & 0.108 \\
\hline 4 & 314295.9 & 4081165.8 & 499.899 & 314295.6 & 4081165.6 & 500.0 & -0.328 & -0.237 & 0.101 \\
\hline 5 & 314248.5 & 4080936.4 & 492.976 & 314248.5 & 4080936.4 & 493.3 & -0.006 & -0.008 & 0.364 \\
\hline 6 & 314238.8 & 4080883.7 & 490.428 & 314238.8 & 4080883.4 & 491.0 & -0.012 & -0.313 & 0.572 \\
\hline 7 & 314317.4 & 4080864.4 & 490.295 & 314317.4 & 4080864.3 & 490.5 & -0.004 & -0.076 & 0.249 \\
\hline 8 & 314141.4 & 4080719.6 & 485.847 & 314141.4 & 4080719.8 & 486.0 & 0.003 & 0.143 & 0.182 \\
\hline 9 & 314040.5 & 4080910.7 & 491.285 & 314040.4 & 4080910.7 & 491.5 & -0.110 & -0.001 & 0.229 \\
\hline 10 & 314079.9 & 4080960.6 & 490.659 & 314079.9 & 4080960.6 & 490.6 & -0.030 & 0.005 & -0.035 \\
\hline 11 & 314079.0 & 4080978.7 & 492.184 & 314078.9 & 4080978.6 & 492.2 & -0.069 & -0.102 & -0.024 \\
\hline 12 & 314049.1 & 4080884.0 & 490.776 & 314049.1 & 4080884.0 & 490.8 & -0.007 & 0.044 & -0.018 \\
\hline & & Mean & & & -0.049 & $-\mathbf{0 . 0 4 9}$ & $\mathbf{0 . 1 4 8}$ \\
\hline & & Standard deviation (St.dev.) & & $\mathbf{0 . 0 9 5}$ & $\mathbf{0 . 1 2 2}$ & $\mathbf{0 . 1 8 3}$ \\
\hline
\end{tabular}

Table ( 6 shows that the range in the horizontal position accuracy is in the order of $3 \mathrm{~mm}$ to $4 \mathrm{~cm}$ in all of the 12 check points on the finally produced orthomosaic using the
AutoCAD civil 3-D. The range of height errors were in the order of $5 \mathrm{~mm}$ to $57 \mathrm{~cm}$. This is mainly obtained due to the surface interpolation process.

Table (7): The mean and standard deviation of the Aerial orthomosaic vs Check points

\begin{tabular}{|c|c|c|c|c|c|c|c|c|c|}
\hline \multirow{2}{*}{$\begin{array}{l}\text { Points } \\
1 \\
\end{array}$} & \multicolumn{3}{|c|}{ GPS check points $(\mathrm{m})$} & \multicolumn{3}{|c|}{$\begin{array}{c}\text { Orthomosaic generated from aerial } \\
\text { survey conducted by German } \\
\text { company }(\mathrm{m})\end{array}$} & \multirow{2}{*}{$\begin{array}{c}\Delta \mathrm{e}(\mathrm{m}) \\
-0.006\end{array}$} & \multirow{2}{*}{$\begin{array}{c}\Delta \mathrm{n}(\mathrm{m}) \\
0.018 \\
\end{array}$} & \multirow{2}{*}{$\begin{array}{l}\Delta \mathrm{h}(\mathrm{m}) \\
-0.268\end{array}$} \\
\hline & 314057.0 & 4081192.7 & 497.963 & 314057.0 & 4081192.7 & 497.7 & & & \\
\hline 2 & 314132.8 & 4081296.5 & 505.268 & 314133.0 & 4081296.9 & 503.2 & 0.198 & 0.334 & -2.057 \\
\hline 3 & 314210.8 & 4081238.0 & 503.388 & 314210.8 & 4081238.0 & 503.4 & 0.001 & -0.002 & -0.010 \\
\hline 4 & 314295.9 & 4081165.8 & 499.899 & 314295.8 & 4081165.8 & 497.5 & -0.090 & -0.034 & -2.393 \\
\hline 5 & 314248.5 & 4080936.4 & 492.976 & 314248.0 & 4080936.2 & 492.6 & -0.493 & -0.239 & -0.412 \\
\hline 6 & 314238.8 & 4080883.7 & 490.428 & 314238.8 & 4080883.3 & 491.4 & 0.010 & -0.388 & 0.940 \\
\hline 7 & 314317.4 & 4080864.4 & 490.295 & 314317.4 & 4080864.3 & 489.6 & -0.017 & -0.094 & -0.658 \\
\hline 8 & 314141.4 & 4080719.6 & 485.847 & 314141.4 & 4080719.9 & 485.2 & -0.030 & 0.218 & -0.686 \\
\hline 9 & 314040.5 & 4080910.7 & 491.285 & 314040.3 & 4080910.7 & 490.9 & -0.162 & -0.065 & -0.402 \\
\hline 10 & 314079.9 & 4080960.6 & 490.659 & 314079.7 & 4080960.6 & 491.4 & -0.193 & -0.015 & 0.788 \\
\hline 11 & 314079.0 & 4080978.7 & 492.184 & 314079.0 & 4080978.6 & 492.3 & -0.035 & -0.105 & 0.086 \\
\hline 12 & 314049.1 & 4080884.0 & 490.776 & 314049.1 & 4080883.7 & 489.8 & -0.042 & -0.222 & -0.959 \\
\hline \multicolumn{7}{|c|}{ Mean } & -0.071 & -0.050 & -0.503 \\
\hline \multicolumn{7}{|c|}{ Standard deviation (St.dev.) } & 0.164 & 0.194 & 0.984 \\
\hline
\end{tabular}

farst.heeto@uod.ac, raadkattan@uod.ac, sami.gyliana@uod.ac

${ }^{1}$ Corresponding author: College of Engineering, University of Duhok, Kurdistan Region 
The discrepancy of $(\Delta \mathrm{e}, \Delta \mathrm{n}$ and $\Delta \mathrm{h})$ were lager and very significant in the elevation when compared with the existing orthomosaic generated from aerial survey conducted by German Company. These large amounts of errors can be attributed to the flying height which is more than UAV flight height, and this can affect the height components greatly, due to relief displacement. In addition, the identification of the position of points cannot be located precisely on the orthomosaic. Another possible cause is the size of the separation of control points distributed over the area, introducing errors in height during the interpolation process. These height errors are represented by column errors of each check point, as shown in the Fig. (13.
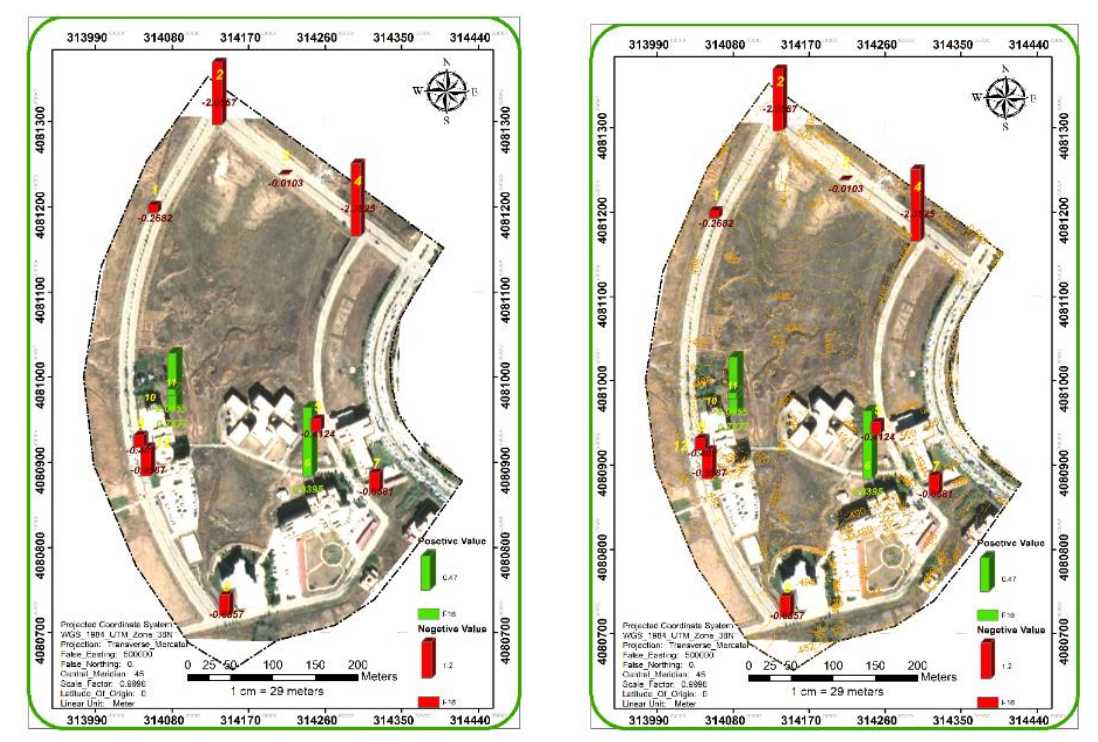

Fig. (13): Height errors of orthomosaic for aerial survey vs check point

\section{RESULT DISCUSSION AND CONCLUSIONS}

The target of this research is to assess the accuracy of the output of UAV produced orthomosaic and the existing orthomosaic conducted by German Company, considering the high accuracy requirements needed on projects such as engineering details mapping.

Based on the result obtained, the UAV images contain high position errors if the process is based only on the embedded GPS (standalone) equipment, see Table1. The error can reach the range of 25-26 $\mathrm{m}$ in positions
Image refinement and incorporating more images that contain the GCPs will significantly reduce the size of error. A few trials will drop the position accuracy to a range of 5-8 $\mathrm{mm}$. This is achieved when utilizing the GCPs control points marked with target plates. The final result, presented in Table (5, shows the horizontal position and height component are within the $\mathrm{cm}$ level of accuracy for the orthomosaic prepared with the AutoCAD Civil 3-D software. However, in some positions of height points, the accuracy degraded due to the misidentification of target points in multiple images, camera calibration, and attitude of the flight height at the time of 
survey and etc.

The results of the orthomosaic obtained from UAV image is acceptable for most of the engineering applications and is more accurate than the existing orthomosaic achieved by the German company.

The accuracy of the existing orthomosaic (German company), has less accuracy than that reaching the level of more than $2 \mathrm{~m}$ in elevation, see Table $(7$.

On orbiting the model in 3-d space, a noticeable error and distortion will be obvious.
Further coverages of building façades are necessary to overcome this drawback.

Another source of error is the difficulties in identifying the centres of the GCPs on the images. Although the targets are clearly marked with high contrast, the centre of the target will be diffused over several pixels on the image as illustrated in Fig. (14)

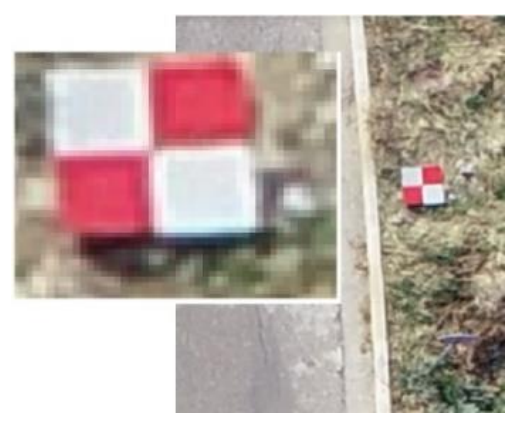

Fig. (14): Misidentification of the target point

\section{ACKNOWLEDGEMENTS}

The authors give thanks to the college of Engineering, department of Surveying Engineering for providing the instrumentation tools of surveying.

\section{REFERENCES}

Brance P. Hudzietz, \& Saripalli., S. (2012). An experimental evaluation of $3 \mathrm{D}$ terrain mapping with an autonomous helicopter. . doi: 10.5194/isprsarchives-XXXVIII-1-C22-137-2011.

DJI. (2018). Flight Controller Data Analysis Series Tutorials (Vol. Part 1, pp. 1-2).

Eisenbeiß, H. (2009). UAV Photogrammetry. Press. In Zurich. DISS. ETH NO. 18515.

Hedgecock, W., Maroti, M., Sallai, J., Volgyesi, P., \& Ledeczi, A. (2013). High-accuracy differential tracking of low-cost GPS receivers. Paper presented at the Proceeding of the 11th annual international conference on Mobile systems, applications, and services.

IDREES M, A., \& ABULRAHMAN, F. H. (2020). EVALUATION OF UAV-BASED DEM FOR VOLUME CALCULATION. Journal of Duhok University. Journal of Duhok University (JDU), Vo.23 ((1)), p.p.11-24. doi: https://doi.org/10.26682/sjuod.2020.23.1.2

Kattan, R., Abdulrahman, F., \& Hassan, H. (2016). Evaluating the accuracy of Google Earth DEM using GPS Coordinates, Case study: Duhok Governorate. Journal of University of Duhok (JDU), 19, 1-16. Kung, O., Strecha, C., Beyeler, A., Zufferey, J. C., Floreano, D., Fua, P., \& Gervaix, F. (2011, 2011 Sep 14-16, Zurich). The accuracy of automatic farst.heeto@uod.ac, raadkattan@uod.ac, sami.gyliana@uod.ac ${ }^{1}$ Corresponding author: College of Engineering, University of Duhok, Kurdistan Region 
photogrammetric techniques on ultra-light UAV imagery. . Paper presented at the UAV-g 2011-Unmanned Aerial Vehicle in Geomatics.

Nagai, M., Tianen, C., Shibasaki, R., Kumagai, H., \& Ahmed, A. (2009). Uav-borne 3-d mapping system by multisensory integration. IEEE Transactions on Geoscience and Remote Sensing, 47 ((3) ), 2371-2388.

Pix4D. (2020). Pix4D. . Retrieved May, 18, 2020 from https://www.pix4d.com/

Wierzbicki, D., Kedzierski, M., \& Fryskowska, A. (2015). Assesment of the influence of uav image quality on the orthophoto production. The International Archives of Photogrammetry, Remote Sensing and Spatial Information Sciences, 40(1), 1. Zietara, A. M. (2017). Creating Digital Elevation Model ( DEM ) based on ground points extracted from classified aerial images obtained from Unmanned Aerial Vehicle ( UAV ). . Norwegian University of Science and Technology Faculty of Engineering. Department of Civil and Environmental Engineering, (June), 1-98.

farst.heeto@uod.ac, raadkattan@uod.ac, sami.gyliana@uod.ac 